\title{
Aspectos Legislativos da Regulação de Medicamentos
}

\author{
LEGAL ASPECTS OF BRAZILIAN MEDICINE REGULATION
}

\author{
Davi Rumel (*) \\ Izabela Nunes Chinchilla ${ }^{(*)}$ \\ Eugênio Rodrigo Zimmer Neves ('“)
}

\section{RESUMO}

Este artigo discute a legislação e os regulamentos sobre medicamentos e exemplos de contradições desses regulamentos com a legislação. Tem por objetivo ampliar o entendimento e a participação social no processo regulatório de medicamentos. Primeiramente, são revistos alguns aspectos da legislação que podem gerar conflitos regulatórios e, posteriormente, apresenta-se uma atualização da legislação específica de registro de medicamentos genéricos, similares, novos e fitoterápicos, de acordo com as regulamentações específicas aprovadas pela Diretoria Colegiada da ANVISA.

\section{Palavras-chave:}

Agência Nacional de Vigilância Sanitária; Legislação; Regulamentação de Medicamentos.

\section{ABSTRACT}

This paper approaches the legislation and rules on medicines and examples of contradictions between them. It has for objective to extend the

(") Médico, Diretor-Adjunto da Agência Nacional de Vigilância Sanitária (ANVISA), Professor Doutor do Mestrado de Saúde Coletiva da UNISUL, Doutor em Epidemiologia. E-mail:davi.rumel@anvisa.gov.br (**) Farmacêutica, Consultora para Assuntos Regulatórios -REGULARE. E-mail:izabelanunes@yahoo.es (***) Farmacêutico, Assessor-Chefe do Núcleo de Gestão da Qualidade da Informação em Medicamentos, Gerência Geral de Medicamentos da Agência Nacional de Vigilância Sanitária (ANVISA), Doutor em Farmácia. E-mail:eugenio.zimmer@anvisa.gov.br. Recebido em 14.6.06. Aprovado em 3.8.06. 
agreement and the social participation in the process of drug regulation. At first, legislation aspects that may generate regulatory conflicts are reviewed. Subsequently, we present an update of the specific legislation of generic, similar, new and herbal medicines, in accordance with the specific regulations approved by the Collegiate Board of Directors at ANVISA.

\section{Key words:}

National Agency of Sanitary Vigilance (ANVISA); Legislation; Medicines Regulation.

\section{INTRODUÇÃO}

$\mathrm{Na}$ qualidade de bem público e cujo uso, não uso ou mau uso afeta a totalidade da população, o medicamento deveria ser monopólio do Estado o qual deveria desenvolvê-lo, fabricá-lo, trabalhar na adequação das formulações disponíveis e colocá-lo gratuitamente à disposição da população. Entretanto, tal característica de acesso gratuito, universal e de monopólio estatal de todo o ciclo de desenvolvimento-produção-distribuição não ocorre em nenhum país do mundo, mesmo naqueles mais econômica ou socialmente avançados. A impossibilidade de o Estado dominar de modo eficiente o ciclo do medicamento torna imperativa a recorrência ao setor privado. $O$ corolário dessa intervenção privada é a transformação do medicamento em uma mercadoria sobre a qual o Estado deve assumir um papel decisivo de controle de mercado, reduzindo a assimetria de informações, impedindo práticas comerciais abusivas (propaganda indutiva) e garantindo a fabricação de produtos com os mais elevados padrões de qualidade possíveis. A intervenção estatal no mercado de bens públicos (como é o caso) deve considerar que o objetivo principal da atividade econômica privada é a maximização da lucratividade, e não necessariamente a melhoria nas condições de vida das populações, e contrabalançar esses interesses com o interesse da população em poder ter acesso a esses produtos.

$\mathrm{Na}$ fase de produção, o controle estatal ocorre por meio da concessão de registro de produto que consiste, em última análise, em uma permissão para a produção de um bem público. Existe, portanto, uma delegação do Estado ao setor produtivo privado da possibilidade de produção de medicamentos consubstanciada pelo ato de registro do medicamento, pelo qual o Estado outorga à empresa o direito de explorar economicamente um ou mais tipos de produtos.

No intuito de não somente reduzir os riscos à saúde da população como também otimizar os benefícios do uso dos medicamentos em um mer- 
cado onde convivem interesses públicos e privados, cabe ao Estado impor regras que demarquem os distintos interesses, tais como: a concessão de autorização de funcionamento, a certificação de que o fabricante cumpre com boas práticas de fabricação e de controle de qualidade (que garantam a reprodutibilidade lote a lote na produção de determinado bem) e o estabelecimento de regras rígidas para o registro de medicamentos. Na implementação desses controles, por meio da edição de normas (restritivas e/ou procedimentais), o Estado busca estabelecer parcerias com o setor privado visando garantir que o preceito constitucional, segundo o qual a saúde é direito de todos e dever do Estado, seja respeitado.

No que tange à forma de normalização do mercado (entendida como o controle rígido que sustenta essa delegação de produção, controle e comercialização ao setor privado), há dois caminhos: o primeiro visa criar um conjunto restrito de regras e deixa a interpretação dessas regras ao sabor da subjetividade; o outro, visa criar o máximo de regras, deixando pouco espaço para a subjetividade. No mercado brasileiro, há até bem pouco tempo imperava a primeira situação; mas, a criação da Agência Nacional de Vigilância Sanitária (ANVISA), em 1999 provocou a inflexão para um panorama normativo mais prescritor e detalhado.

A primeira abordagem favorece a expansão do mercado com um risco significativo da redução da qualidade dos produtos ofertados. A segunda tende a causar uma retração de mercado (menor número de unidades produtoras são capazes de adequar-se às regras rígidas), mas tende a favorecer o aumento significativo da qualidade dos produtos ofertados.

Foi nesse contexto e considerando o debate sobre o marco regulatório que se desejava implantar no país que a ANVISA foi criada em 1999. Comparado com os Estados Unidos da América (cujo órgão regulador, o Food and Drug Administration [FDA], foi criado em 1927), o Brasil encontra-se na primeira infância regulatória com respeito a medicamentos.

O processo de transição entre um modelo de regulação esparsa e subjetivamente interpretada para um estrito e prescritivo é problemático sob diversos aspectos, principalmente no que tange aos interesses econômicos contrariados pelo novo marco regulatório. Para reduzir esse atrito, a ANVISA, desde sua criação, tem utilizado o instrumento da Consulta Pública para a aprovação e publicação de novas normas. Tal prática visa estabelecer um mecanismo através do qual a sociedade civil possa se manifestar sobre a totalidade da legislação proposta, permitindo que o ordenamento jurídico se estabeleça com menos conflitos, ao mesmo tempo em que consolida os interesses comuns. Essa redução de conflitos permite que a posterior fiscalização por parte do Estado seja mais simples e eficiente. $O$ instrumento da consulta pública permite, assim, a construção de políticas públicas duradouras pactuadas entre os diferentes atores do marco regulatório. 
Este artigo objetiva discutir a legislação específica e os regulamentos incidentes sobre medicamentos no Brasil, bem como exemplos de contradições com a legislação federal.

\section{CONTRADIÇOEES COM A LEGISLAÇÃO}

O Congresso Nacional é o poder soberano para a aprovação de legislação sobre medicamentos no país. Tal soberania, no entanto, não está livre da influência de diversos grupos econômicos que competem entre si para que o Estado atenda seus interesses, o que dificulta ao país estabelecer marcos regulatórios sólidos (característica desejável e fundamental para o desenvolvimento tanto do setor privado como do público na área de medicamentos).

A possibilidade de o Congresso Nacional estabelecer modificações no marco regulatório que impliquem em retrocessos (sob o aspecto sanitário) à atual regulamentação do mercado de medicamentos obriga o agente regulador (ANVISA) a possuir uma assessoria específica, que acompanhe os projetos em discussão no parlamento e simultaneamente informe os demais órgãos implicados no ordenamento jurídico de medicamentos (Ministério da Saúde, Frente Parlamentar da Saúde etc.) sobre possíveis ameaças ao ordenamento jurídico presente e a continuidade de políticas públicas pactuadas com a sociedade.

Por outro lado, para que a ANVISA cumpra eficientemente seu papel de órgão regulador, faz-se necessário que o Congresso Nacional efetive alterações em leis relacionadas com a regulamentação de medicamentos, algumas ainda da década de 70 do século XX. Em sua época, essas leis foram fundamentais para estabelecer o marco regulatório nacional de medicamentos. Porém, é de se esperar que com o passar dos anos e com o avanço da ciência e da tecnologia alterações se façam necessárias.

A seguir, são abordados alguns exemplos da necessidade de modificações à legislação.

A Lei n. 9.787, de 10 de fevereiro de 1999, que estabelece as normas legais para a instituição do medicamento genérico no país, define "medicamento de referência" como sendo um:

"produto inovador registrado no órgão federal responsável pela vigilância sanitária e comercializado no País, cuja eficácia, segurança e qualidade foram comprovadas cientificamente junto ao órgão federal competente, por ocasião do registro."

Porém, nem nessa lei nem em qualquer outro texto legislativo brasileiro se define o conceito de "medicamento inovador", que é essencial. Tal 
indefinição legal faz com que, ao pleitear a renovação de um produto originalmente registrado como novo após a expiração de sua patente, o seu registro deva ser renovado como medicamento similar, pois a definição legal de "medicamento novo" exige que este esteja sob proteção patentária conforme demonstrado na Fig. 1. Como a legislação brasileira, regulamentada pela ANVISA, obriga que o medicamento similar apresente provas de bioequivalência com seu produto de referência, estabelece-se uma situação esdrúxula: exigir bioequivalência de um produto consigo mesmo. A ANVISA, na prática, isenta esses produtos da apresentação dessa prova, mas, existe um vazio legal que impede uma solução correta para a situação.

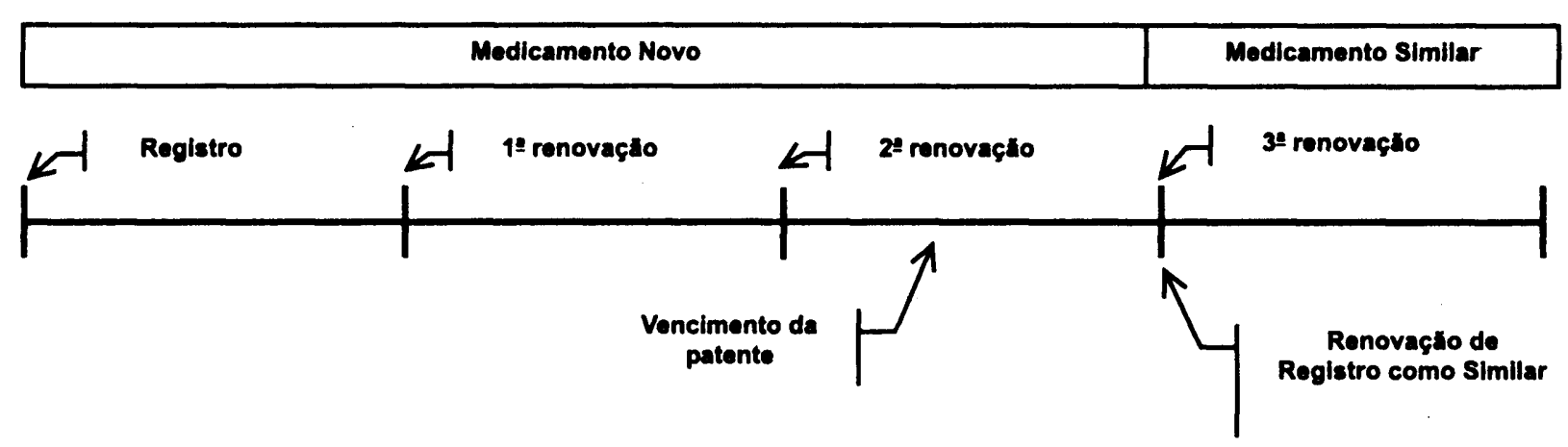

Fig. 1 - Cronograma de renovação de registro de medicamento novo e expiração patentária

Outra contradição no marco legislativo de medicamentos é a necessidade de uma alternativa que permita o registro de um medicamento registrado como "medicamento novo" que, por qualquer motivo, tenha perdido seu prazo de revalidação ou a empresa vendeu sua marca para outra empresa (fato que gera a necessidade de um novo registro para o medicamento). Como esse produto não pode mais ser considerado uma molécula nova, não cabe ser registrado como medicamento novo, tampouco como medicamento similar, já que ele possui seus próprios estudos de segurança e eficácia. O vazio legal manifesta-se na impossibilidade de enquadrar adequadamente esse produto para que possa ser utilizado como medicamento de referência para testes de biodisponibilidade. Tal vácuo poderia ser preenchido com a criação de uma nova categoria de medicamentos: os medicamentos inovadores.

Por imposição legal, a ANVISA não pode criar novas categorias de medicamentos por iniciativa própria (criação implica em novas definições e, conseqüentemente, em distintas taxas de arrecadação). Assim, a resolução do conflito acima descrito requer a edição e a promulgação de legislação específica que crie a seguinte definição legal: 
"Medicamento Inovador: Aquele que realizou originalmente os estudos de eficácia e segurança para as indicações terapêuticas aprovadas pela ANVISA."

A redefinição de medicamento de referência também é importante para dirimir dúvidas sobre sua exata abrangência e definição:

"Medicamento de Referência: aquele cuja segurança, eficácia e qualidade tenham sido comprovadas cientificamente junto ao órgão federal competente."

Parágrafo único: "O Medicamento de referência será preferencialmente o novo ou o inovador."

A definição legal de Medicamento Inovador e de Medicamento de Referência permitirá flexibilizar a escolha deste último, pois muitas vezes o produto novo ou inovador já não é mais comercializado. A desobrigação de definir Medicamento de Referência somente entre aqueles registrados como novos ou inovadores permitirá à ANVISA elaborar uma regulamentação acordada em consulta pública para definir os critérios de escolha de um medicamento de referência, o que é fundamental para a expansão da política de genéricos e de qualificação de todo o mercado farmacêutico brasileiro.

As definições e vazios legais da legislação brasileira também dificultam o controle e rastreabilidade de produtos. Outro exemplo que impede a execução mais efetiva dessas ações é a definição de registro pela Lei 6.360 , de 23 de setembro de 1976 que, em seu art. $3^{\circ}$, inciso $X$, define registro como:

"Registro: inscrição, em livro próprio após o despacho concessivo do dirigente do órgão do Ministério da Saúde, sob número de ordem, dos produtos de que trata esta Lei, com a indicação do nome, fabricante, da procedência, finalidade e dos outros elementos que os caracterizem"; ...

O mercado farmacêutico atual, caracterizado mundialmente por uma forte tendência à concentração de empresas e capital, leva à necessidade da criação de acordos comerciais, em que a empresa que realiza a pesquisa não é necessariamente a empresa que fabrica o produto, que, por sua vez, não é obrigatoriamente quem embala, promove ou vende os produtos finais. A atual legislação brasileira para o registro de medicamentos, conforme demonstrado pela definição legal de registro, admite que somente uma empresa pode ser a detentora do registro. Entretanto, em um mercado mutante e segmentado como o atual, diferentes empresas podem possuir diferentes registros de um mesmo medicamento (para isso, basta ser fabricado em um mesmo lugar), conforme ilustrado pela Fig. 2. Essa diversidade de registro para um mesmo produto cria sérios problemas de rastreabilidade para o monitoramento pós-mercado, principalmente quando existe um alerta 
de segurança sanitária ou confirmação de desvio de qualidade e existe a necessidade de recolher um produto do mercado. Corre-se o risco de retirar os medicamentos XB, mas deixar os XC e XD, fabricados pelo mesmo laboratório.

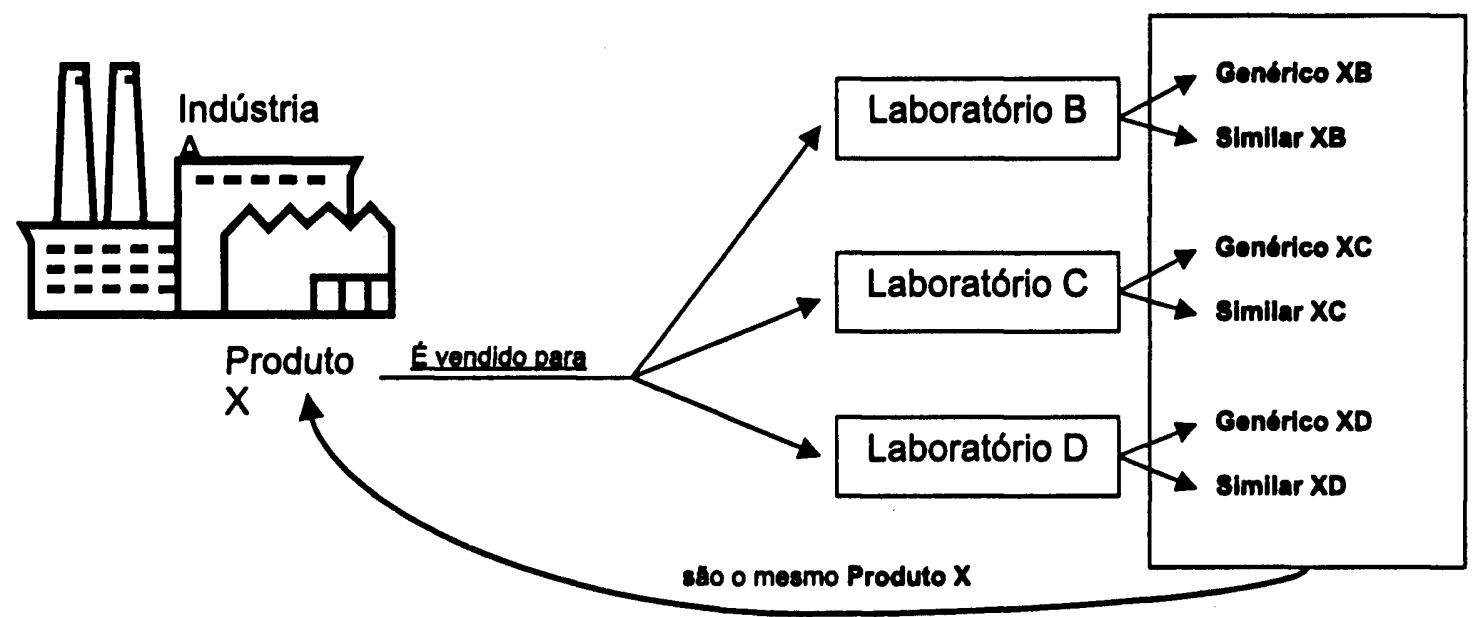

Fig. 2 - Rastreabilidade de medicamentos

Há também o fato de que boa parte da indústria de similares que migrou para a produção de genéricos não deixou o mercado com o nome comercial que já havia conquistado. Manteve os dois, ou seja, o mesmo produto um dia é embalado como genérico e em outro dia, como similar.

Tal situação certamente pode ser administrada por um sistema de informações planejado e mantido de forma adequada. Entretanto, gera-se um grande desperdício de recursos económicos, burocráticos e humanos, pois a ANVISA deve analisar diversas vezes registros e alterações pós-registro de um mesmo produto (que em muitas ocasiões só se diferencia pela embalagem externa), criando um acúmulo desnecessário de trabalho.

Para aumentar a eficiência da ANVISA $\Theta$ facilitar a rastreabilidade desses medicamentos, criou-se a proposta de extensão de comercialização de um mesmo registro para mais duas empresas diferentes, ou entre um genérico e sua apresentação para o mercado de similares. Porém, isto não é legalmente possível, pois a lei vincula cada registro a uma única empresa e nome distintos.

Caso se remova dessa definição a vinculação do registro ao nome, será possível criar a figura da extensão de comercialização e passar a regulamentar efetivamente, após consulta pública, uma situação que já existe de fato.

Por ocasião da nova redação desse artigo, foi possivel incluir a definição de extensão de comercialização:

"Extensão de comercialização: alteração pós-registro que permite que o mesmo produto de um mesmo detentor com um único registro tenha identificações diferentes para fins de comercialização. Tal alteração deve ser regulamentada pela ANVISA." 
A modernização e os avanços alcançados pela ANVISA nos últimos anos requerem a consolidação do marco regulatório atual e a inclusão e/ou redefinição de conceitos presentes na legislação. Cabe ao Congresso Nacional legislar soberanamente sobre medicamentos, garantindo o aumento da segurança e eficácia dos medicamentos comercializados no Brasil.

\section{ATUALIZAÇÃO DA LEGISLAÇÃO ESPECÍFICA}

\subsection{O registro de genéricos e o registro de similares}

Ao término da vigência da patente do produto inovador, a ANVISA autorizou o registro de medicamentos genéricos (os medicamentos similares não estão vinculados à patente). Como as matérias-primas desses medicamentos têm procedência variada, eles são denominados em inglês de multisource products.

Os genéricos foram criados por meio da Lei n. 9.787/99. A edição dessa norma representou um redirecionamento político do Ministério da Saúde e da ANVISA e teve como objetivo criar um novo padrão para a qualidade dos "medicamentos cópia", mais conhecidos como similares (os únicos existentes até então). Tal redirecionamento foi estabelecido de acordo com padrões internacionais adotados em vários países para os multisource products e reconhecidos pela Organização Mundial da Saúde (OMS).

No ato do registro, os medicamentos genéricos devem comprovar sua equivalência com o medicamento eleito como de referência em termos de eficácia e segurança, tanto com provas in vitro - laboratoriais (equivalência farmacêutica), como in vivo - ensaios clínicos (bioequivalência). Além disso, as empresas que requerem o registro desses medicamentos devem possuir Certificados de Boas Práticas de Fabricação e Controle para a linha de produção e para a forma farmacêutica do produto que pretendem registrar. Essas três exigências constituem-se nos fundamentos básicos de uma política de medicamentos: garantir que todos os medicamentos comercializados possuam qualidade, segurança e eficácia.

Após a publicação da Lei n. 9.787/99, continuaram a conviver no mercado brasileiro os medicamentos similares (que não realizaram testes de equivalência farmacêutica ou de bioequivalência) e os medicamentos genéricos (que realizaram todos os testes para entrar no mercado). Essa situação representava, claramente, uma elevada assimetria em que produtos de qualidade e segurança comprovadas concorriam com produtos que não haviam sido submetidos aos testes. Para enfrentar tal situação, a ANVISA, após consulta pública, aprovou a RDC n. 134, de 29 de maio de 2003, na qual foi estabelecido um cronograma para que os medicamentos similares já registrados também comprovassem sua equivalência in vitro e in vivo, exata- 
mente como os genéricos. Esse cronograma foi arduamente discutido com a sociedade, levando sempre em consideração o princípio constitucional da razoabilidade e da saúde como direito de todos e dever do Estado.

Estabeleceu-se o prazo de um ano e meio após a publicação da RDC n. 134/03 para que as empresas detentoras de registros de medicamentos similares de margem terapêutica estreita ${ }^{(1)}$ apresentassem testes de biodisponibilidade relativa (equivalência in vivo).

A partir de dezembro de 2004 , ou seja, um ano e meio após a publicação da norma, até 2009, todos os medicamentos similares devem apresentar o resultado da equivalência farmacêutica (equivalência in vitro). Tal medida, considerando que o medicamento de referência é eleito pela ANVISA, elimina do mercado produtos registrados como cópias, mas que na realidade realizaram algum tipo de inovação cuja eficácia e segurança não foram comprovadas no ato do registro desse medicamento.

Concomitante a essa adequação, os medicamentos considerados pela ANVISA por meio da RE n. 532, de $1^{\circ}$ de março de 2005 como sendo antibióticos, antineoplásicos e anti-retrovirais também devem comprovar, além da equivalência in vitro, a equivalência in vivo. A escolha dessas classes de medicamentos deve-se ao fato de que é imperativo que apresentem eficácia elevada, uma vez que sua falta de efetividade pode colocar em sério risco a saúde e a vida dos pacientes.

A partir de dezembro de 2009 até 2014, todos os medicamentos similares das demais classes terapêuticas devem comprovar sua equivalência in vivo, desde que não sejam isentos desta prova em função da sua respectiva forma farmacêutica e categoria de venda(2).

A Fig. 3 detalha o cronograma de adequação do mercado de medicamentos similares à RDC n. 134/03.

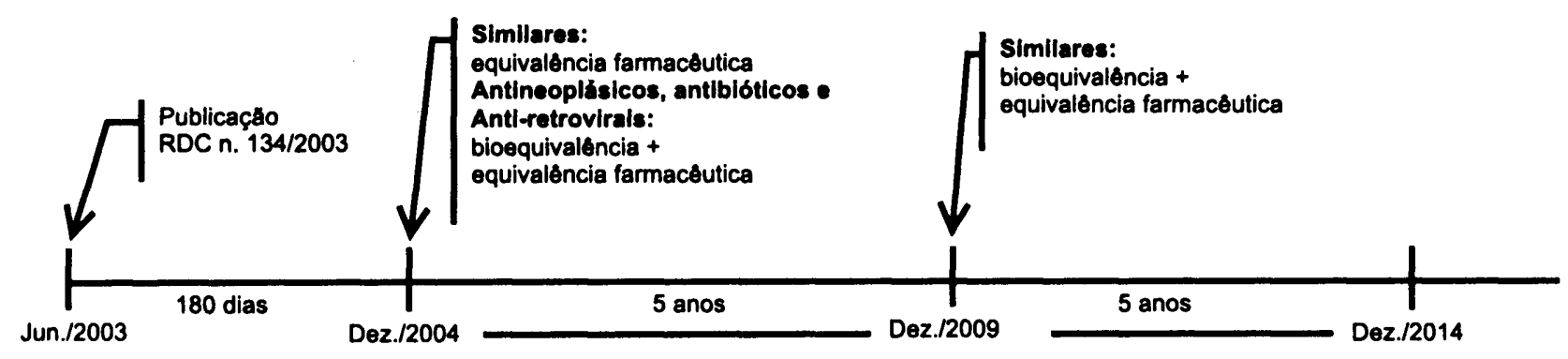

Fig. 3 - Adequação do mercado de medicamentos similares à $R D C$ n. $134 / 03$

(1) Aqueles cujo efeito tóxico e o terapêutico em uma dose são muito próximos.

(2) Estão dispensados de apresentar essas provas os medicamentos em solução, injetáveis, tópicos e de venda isentos de prescrição médica. 
Ao final de 2014, a adequação do mercado de similares à RDC n. 134/03, o que diferenciará um medicamento genérico de um medicamento similar registrado, passará a ser unicamente a presença ou não de um nome comercial, tendo em vista que os genéricos só podem ser comercializados utilizando a denominação comum brasileira como identificação do produto. Não mais haveria produtos diferenciados com respeito à qualidade, eficácia ou segurança em sua utilização.

A única diferenciação entre os produtos será então a possibilidade de intercambialidade, já que, segundo a legislação brasileira, apenas os medicamentos genéricos podem ser intercambiados pelo responsável pela dispensação do medicamento na drogaria ou farmácia, a não ser que o prescritor registre expressamente na receita que não autoriza essa prática. Para facilitar a intercambialidade e garantir que os consumidores identifiquem claramente os produtos genéricos dos demais, sua rotulagem possui uma apresentação peculiar de fácil identificação. Além dessa diferenciação formal, na prática, até 2014 , os medicamentos genéricos podem apresentar uma qualificação superior ao conjunto de medicamentos similares, tendo em vista que, desde sua criação, foram obrigatórias, para a aquisição do registro, as comprovações de equivalência in vitro e in vivo. Já o similar, conforme demonstrado, apresentará essas equivalências ao longo de alguns anos. Após 2014, caberá ao Estado redefinir a manutenção ou não de produtos de mesma qualidade em categorias diferentes, tendo como principal distinção as regras de nomenclatura.

\section{O REGISTRO DE FITOTERÁPICOS}

Há grande número de medicamentos sintéticos ou semi-sintéticos que têm como origem um princípio ativo vegetal. Conseguiu-se isolar a molécula ativa e sintetizá-la. Porém, existe ainda uma série de derivados de plantas que possuem ação terapêutica, mas que não tiveram ainda a(s) molécula(s) ativa(s) identificada(s) e ou isolada(s).

Plantas de mesma espécie podem mudar o teor de seus compostos conforme o terreno e o clima em que se desenvolveram. Para garantir que a produção em série de um fitoterápico tenha o mesmo conteúdo a cada lote produzido, os derivados de planta (extratos, resinas, óleos e essências) são manipulados até atingir a concentração ideal de uma molécula, que pode ou não ser ativa: são os denominados marcadores. Para o controle de qualidade de um fitoterápico, é fundamental identificar o(s) marcador (es) específicos(s) e comprovar como este(s) será(ão) identificado(s) e quantificado(s) ao longo do processo de produção, lote a lote. $O$ uso de fitoterápicos sem essa garantia pode levar a efeitos tóxicos agudos ou crônicos ou à falta do efeito desejado, em razão da variação de teores dos produtos químicos presentes nas plantas. 
A legislação que dispõe sobre o registro de fitoterápicos exige a apresentação de estudos de toxicidade pré-clínica, aguda e de longa duração envolvendo duas espécies de mamíferos, sendo uma roedora e outra nãoroedora. A comprovação da eficácia e da segurança de um fitoterápico pode apresentar variações que não existem em medicamentos de origem sintética ou semi-sintética. A eficácia e a segurança podem ser comprovadas por meio de ensaios clínicos como os demais medicamentos novos; mas, também, existe a possibilidade de comprovação pelo uso tradicional, utilizando estudos de meta-análise ou por meio de um conjunto de artigos publicados na literatura científica. Uma comissão de peritos, com o auxílio de pareceres técnicos de especialistas, toma decisões consensuais nessa área.

\section{O REGISTRO DE NOVOS MEDICAMENTOS}

Para a aprovação do registro de um novo medicamento, cuja definição legal é "sal ou molécula nova e que tenha proteção patentária", a ANVISA, em geral, segue os padrões de avaliação estabelecidos internacionalmente. A concessão do registro depende da aprovação de estudos clínicos Fase III e também está vinculada à aprovação do preço, pelo órgão interministerial denominado Câmara de Medicamentos - CMED, cuja secretaria executiva faz parte da ANVISA.

O órgão regulatório também trata como novo medicamento uma molécula já conhecida; porém, veiculada para uso em uma forma farmacêutica, concentração ou via de administração inéditas, medicamentos que apresentem indicações terapêuticas inovadoras, um isômero de uma molécula já registrada, uma associação de princípios ativos estudados isoladamente; mas, nunca antes estudados em associação. Além disso, também é considerada pela ANVISA como novo produto uma molécula sobejamente conhecida que, ao sofrer uma alteração na sua formulação, tem suas propriedades farmacocinéticas alteradas e distintas do medicamento de referência eleito pela ANVISA.

As novas moléculas podem representar uma ampliação do arsenal terapêutico, sendo utilizadas em situações para as quais ainda não se conhecia tratamento, ou podem ser mais uma alternativa terapêutica para um tratamento já conhecido. Esta última opção é denominada de me-too drug e geralmente ocorre por modificações moleculares em uma estrutura química identificada como a parte ativa da molécula. Entretanto, no ato do registro, reconhecer um me-too não é tarefa fácil, tendo em vista que algumas características desses me-toos só podem ser percebidas após sua utilização em larga escala. Entre essas características destacam-se a ocorrência de eventos adversos raros, novos ou sua inexistência, a identificação de subgrupos de indivíduos que se beneficiariam com o novo produto e a descoberta de novas indicações terapêuticas, em particular. 
Cabe lembrar que o efetivo conhecimento quanto à eficácia e à segurança de um novo medicamento, não importa quão precisos e corretos tenham sido os ensaios clínicos, só pode ser determinado quando o produto passa a ser utilizado por milhares de pessoas, ou seja, após a concessão do registro. O conhecimento sobre o uso em larga escala de um produto é monitorado pela farmacovigilância, que pode detectar e identificar novas reações adversas ou falhas terapêuticas a respeito desse novo produto.

\section{CONSIDERAÇOES FINAIS}

É função do Estado mediar os distintos interesses envolvidos no mercado de medicamentos, de forma que os diferentes atores envolvidos (fabricantes, distribuidores, e usuários) não imponham seus desejos de forma unilateral sobre o interesse coletivo. Cabe ao Estado desenvolver mecanismos que favoreçam a competição e a qualificação do mercado, reduzindo a concorrência desleal, o monopólio e o favoritismo para ampliar o acesso da população a medicamentos com o máximo de qualidade, segurança e eficácia.

Para cumprir tal fim, o Estado brasileiro criou a Agência Nacional de Vigilância Sanitária, que utiliza a consulta prévia à sociedade de forma sistemática para regulamentar aqueles assuntos com maior potencial de conflito. Essa forma de consulta estabelece um mecanismo por meio do qual a sociedade pode se manifestar sobre a totalidade da regulamentação proposta, estabelecendo um ordenamento regulatório menos conflituoso e que consolida os interesses comuns.

A criação da ANVISA permitiu ao Brasil migrar de um marco regulatório disperso e marcado por elevada subjetividade na aplicação e interpretação da legislação para um marco muito mais prescritivo e detalhista. Se por um lado essa característica sinaliza ao mercado o interesse do Estado na elevação da qualidade dos produtos ofertados, por outro, a dinâmica econômica do mercado (fusões, incorporações e aquisições de empresas) e a dinâmica tecnológica (novos produtos, meios de produção e controle etc.) muitas vezes tornam rapidamente obsoletos os mecanismos legais e regulatórios (em virtude de sua especificidade e precisão características), provocando a necessidade de uma atualização permanente.

Outro aspecto de vital importância para a consolidação da regulação de mercado na área de medicamentos é a estreita sincronia entre o Congresso Nacional e a ANVISA. 